\title{
ESTUDO DO FENÔMENO DE CORROSÃO NA PONTE MARECHAL HERMES NO RIO SÃO FRANCISCO
}

Fabiana Malta Brinck ' Luiz Cláudio Cândido ${ }^{2}$

Francisco de Assis das Neves ${ }^{3}$

\section{Resumo}

A corrosão é uma das causas mais importantes da deterioração de pontes metálicas. Entre os vários fatores contribuintes para instaurar e acelerar o processo de corrosão em pontes metálicas, podem-se citar o envelhecimento das pontes, o aumento da carga de tráfego, ataque ambiental e, algumas vezes, a inadequação de projetos, detalhamento e construção da estrutura. A degradação em geral começa no ponto mais debilitado da estrutura, sendo, portanto, necessário procurar por evidências visuais de sua ocorrência. A ocorrência e extensão dos danos e defeitos encontrados em inspeções sucessivas são usadas para estimar a deterioração de componentes estruturais. Os resultados dessas inspeções servem, portanto, como critério na tomada de decisão para a aplicação de medidas de manutenção e reabilitação. O objetivo deste trabalho é investigar e diagnosticar o fenômeno de corrosão desenvolvido na Ponte Marechal Hermes (PMH), sobre o Rio São Francisco, que se encontra num estado avançado de degradação, além de descrever a metodologia adotada de inspeção.

Palavras-chave: Pontes; Inspeção; Corrosão.

\section{STUDY OF CORROSION IN THE MARECHAL HERMES BRIDGE OVER SÃO FRANCISCO RIVER}

\begin{abstract}
Corrosion is one of the most important causes of deterioration of steel bridges. Among the various factors that contribute to initiate and to accelerate the process of corrosion in steel bridges, it can be cited the ageing of the bridges, increasing in the traffic load, environmental attack and, some times, due to poor design, detailing and construction of the structure. The degradation usually starts at the weakest point of the structure, being, therefore, necessary to look for visual evidences of its occurrence. The occurrence and extension of damages and defects found in successive inspections are used to estimate the deterioration of structural components. The results of these inspections serve, therefore, as a criterion to make decision for the application of measures for maintenance and rehabilitation. The objective of this work is to investigate and to diagnosis the phenomenon of corrosion developed in the Marechal Hermes bridge (PMH), over San Francisco River, which it is in an advanced state of degradation, besides describing the adopted methodology of inspection.
\end{abstract}

Key words: Bridges; Inspection; Corrosion.

\section{INTRODUÇÃO}

O fenômeno de corrosão ocorre de maneira espontânea, particularmente em estruturas metálicas, em decorrência de projeto inadequado, além do não emprego de manutenção periódica. ${ }^{(1-7)}$

A Ponte Marechal Hermes é uma ponte ferroviária metálica, em treliça, com ligações rebitadas e apoiando-se em pilares de pedra. A ponte foi inaugurada em 1922 e tem uma extensão de 694 metros. Atualmente, a ponte não se encontra em operação com o fim para a qual foi projetada. As passarelas servem para tráfego de pedestres, motos e veículos de tração animal e foram colocadas tábuas ao lado dos trilhos, apoiando-se sobre os dormentes, para o tráfego de automóveis sob baixa velocidade, pela estrutura principal da ponte. A Figura I apresenta uma visão em perspectiva da $\mathrm{PMH}$.

\section{PROCEDIMENTO EXPERIMENTAL}

Foram feitas duas visitas à ponte, com o objetivo de se coletar dados. A primeira foi bastante

'Engenheira Civil, M.C. Rua Castelo de Tordesílhas nº I00 apt. 30I - Castelo - 3I330-230 - Belo Horizonte - MG. fmbrinck@terra.com.br ${ }^{2}$ Engenheiro Metalalúrgico; M.C.; D.C.; Membro da ABM; Prof. Adjunto; Grupo de Estudos sobre Fratura de Materiais; Departamento de Engenharia Metalúrgica e de Materiais. Escola de Minas da Universidade Federal de Ouro Preto. Campus Universitário Morro do Cruzeiro, s/n. Bauxita - 35400-000 - Ouro Preto - MG. candido@em.ufop.br

${ }^{3}$ Engenheiro Civil.; M.C.; D.C.; Prof. Adjunto; Departamento de Engenharia Civil - Escola de Minas da Universidade Federal de Ouro Preto. Campus Universitário Morro do Cruzeiro, s/n. Bauxita -35400-000 - Ouro Preto-MG. fassis@em.ufop.br 


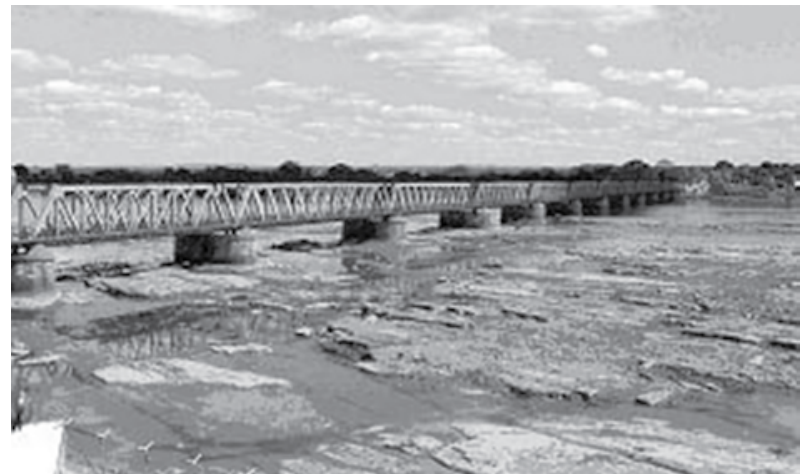

(a)

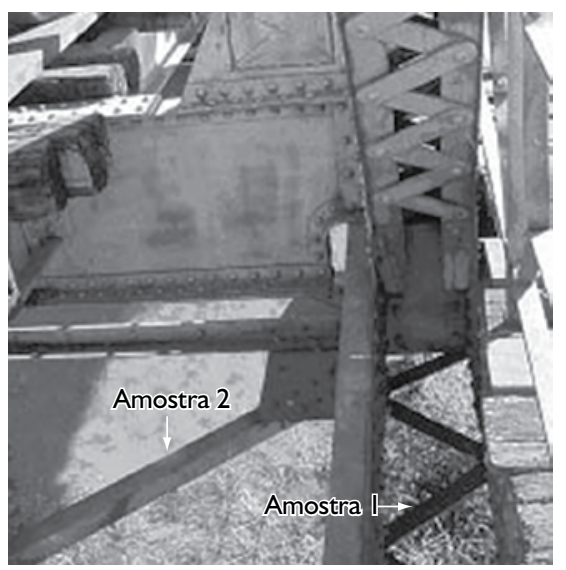

(b)

Figura I. a) Visão em perspectiva da Ponte Marechal Hermes; e b) locais onde foram retiradas as amostras para análises da $\mathrm{PMH}$.

valiosa para se tomar conhecimento no que diz respeito à estrutura, ao sistema estrutural da ponte, aos sistemas portantes e de transmissão de cargas e às condições globais da estrutura, além de permitir o conhecimento dos dados que deveriam ser coletados numa visita futura. A segunda, com duração de dois dias, constituiu-se em uma investigação mais detalhada do que já havia sido notado anteriormente. Nessa visita, fez-se um levantamento da geometria de cada perfil que compõe a PMH com suas respectivas dimensões, além da retirada de material para análise. Uma grande quantidade de fotos registrou o processo corrosivo instaurado em muitas peças e conexões. Foi utilizada também uma câmera de vídeo para possibilitar tomadas mais abrangentes dos danos localizados em relação à peça como um todo. Nas amostras retiradas foram feitas análises química, mecânica e metalográfica. A Figura Ib indica os locais de onde foram retiradas as amostras para análises.

\section{RESULTADOS E DISCUSSÃO}

Para a análise química foram utilizadas duas amostras. A Tabela I apresenta a composição química das amostras analisadas.

Tabela I. Composição química das amostras (\% peso).

\begin{tabular}{cccccccc}
\hline Elementos & $\mathbf{C}$ & $\mathbf{M n}$ & $\mathbf{P}$ & $\mathbf{S}$ & $\mathbf{N i}$ & $\mathbf{C r}$ & $\mathbf{S i}$ \\
\hline Amostra I & 0,034 & 0,346 & 0,049 & 0,023 & 0,047 & 0,016 & - \\
Amostra 2 & 0,238 & $\mathrm{I}, 200$ & 0,012 & 0,012 & 0,008 & 0,012 & 0,019 \\
\hline
\end{tabular}

Tecnologia em Metalurgia e Materiais, São Paulo, v.4, n.3, p. 56-62, jan.-mar. 2008
O ensaio metalográfico foi feito nas duas amostras retiradas de elementos da ponte. A Figura 2a,b mostra as fotomicrografias das amostras I e 2, respectivamente. Nota-se na amostra I (AISI 1005) que a microestrutura é constituída praticamente de ferrita, por se tratar de um aço com baixíssimo teor de carbono, portanto, com características mecânicas de alta plasticidade. Já a amostra 2 (AISI II23), com maior teor de carbono, apresenta uma microestrutura com a fase ferrita e o constituinte perlita.

O ensaio de tração foi realizado a partir da amostra I. Nota-se que a resistência à tração desta amostra é compatível com as de um aço A36. Os resultados do ensaio de tração são apresentados na Tabela 2.

Por inspeção visual foi possível identificar as seções transversais das barras que compõem PMH. É possível observar que, apesar de alguns elementos terem as seções transversais com mesma geometria, suas dimensões são diferentes. A Figura 3a-c apresenta a geometria de algumas seções transversais dos elementos que compõem a PMH.

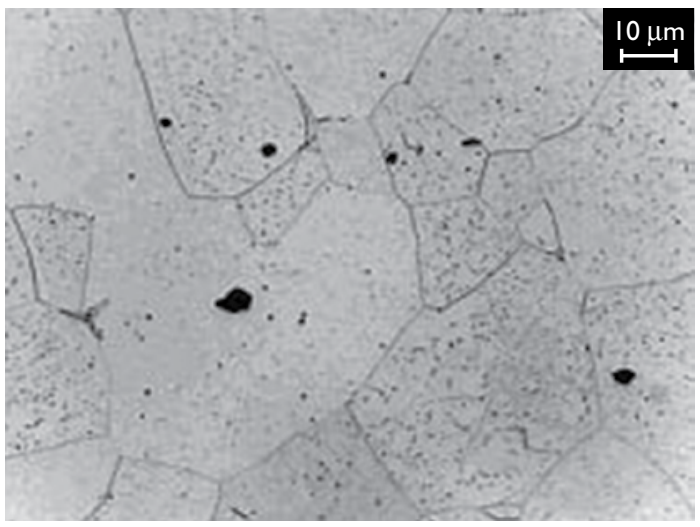

(a)

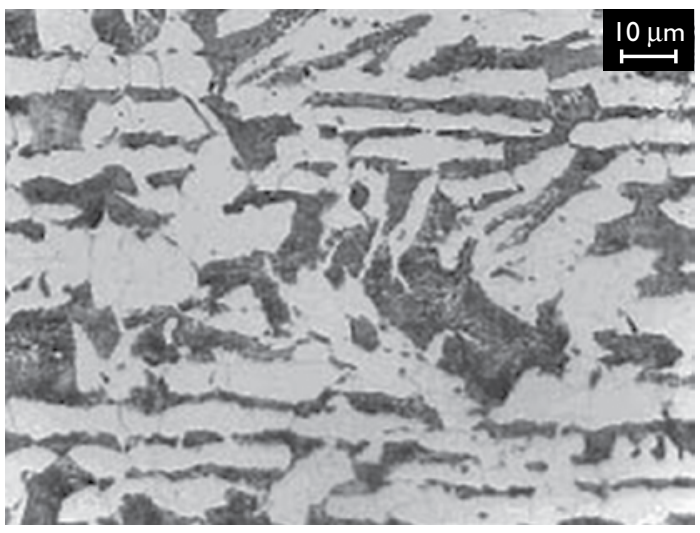

(b)

Figura 2. Fotomicrografias dos aços da $\mathrm{PMH}$ : a) amostra I (do tipo AISI I005); e b) amostra 2 (aço do tipo AISI I I 23); ferrita (claro) e perlita (escuro). Ataque: Nital 2\%. Aumento: I.000x. 
Tabela 2. Resultados do ensaio de tração da amostra I.

\begin{tabular}{ccccccc}
\hline $\mathbf{C P}$ & $\mathbf{F}_{\text {max }}(\mathbf{k N})$ & $\mathbf{F}_{\mathbf{e}}(\mathbf{k N})$ & $\left.\mathbf{f}_{\text {máx }} \mathbf{( M P a}\right)$ & $\mathbf{f}_{\mathbf{e}}(\mathbf{M P a})$ & $\mathbf{A}(\%)$ & $\delta(\%)$ \\
\hline $\mathrm{I}$ & 30,45 & 15,10 & 613,91 & 304,38 & 50,30 & 22,35 \\
2 & 34,35 & 16,48 & 574,13 & 275,45 & 62,19 & 35,00 \\
3 & 33,55 & 12,85 & 556,27 & 213,06 & 60,21 & 35,00 \\
4 & 31,35 & 16,57 & 550,00 & 290,70 & 57,89 & 35,00 \\
\hline
\end{tabular}

$\mathrm{F}_{\mathrm{e}}$ e $\mathrm{f}_{\mathrm{e}}$ - carga e tensão de escoamento no momento em que o primeiro decréscimo de força é observado; $F_{\text {máx }}$ e $f_{\text {máx }}$ - força máxima e resistência à tração; \% A redução de área (estricção); e \% $\delta$ - deformação.

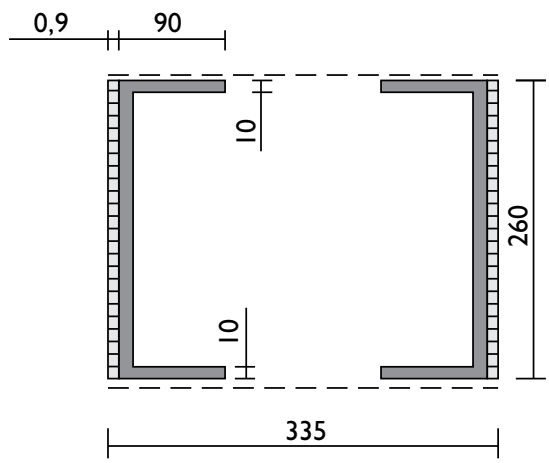

(a)

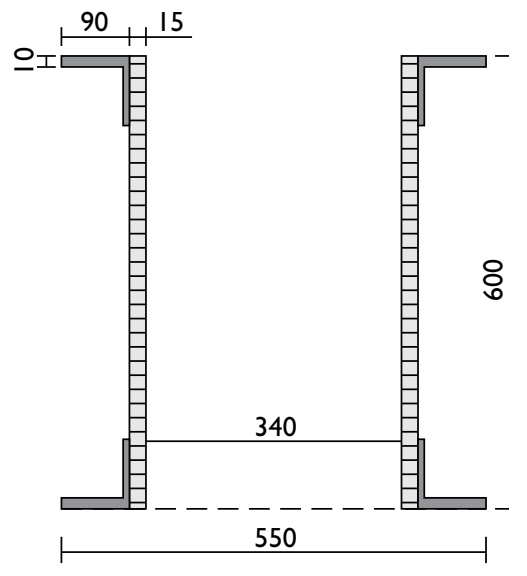

(b)

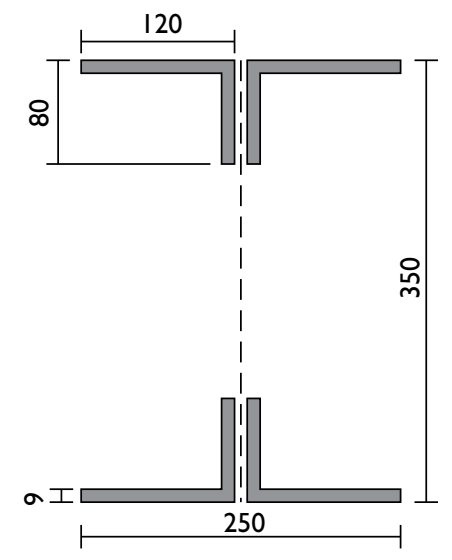

(c)

Figura 3. Geometria de algumas seções transversais dos elementos que compõem a $\mathrm{PMH}$.
A inspeção visual também possibilitou o levantamento dos locais com maiores problemas de corrosão. Foi possível perceber que, de um modo geral, os pontos de corrosão parecem repetir-se nos vários vãos da $\mathrm{PMH}$. Dentre esses pontos os que mais chamam a atenção são os que se encontram na região de ligação das treliças das passarelas com o banzo inferior da treliça principal. Em alguns pontos da $\mathrm{PMH}$, os rebites que compõem as seções transversais dos elementos já foram completamente deteriorados. Em sua parte aérea, no entanto, a PMH apresenta apenas uma corrosão superficial. Os apoios também se encontram deteriorados de modo a colocar em dúvida seu desempenho. Além disso, é preciso dar atenção ao treliçamento que compõe o perfil do banzo inferior da treliça principal, por apresentar tal grau de deterioração, que algumas barras já se encontram rompidas.

A Figura 4a,b apresenta, principalmente, o tipo de corrosão generalizada (uniforme) na PMH; no entanto, pode haver também corrosão localizada. Estas regiões, geralmente, encontram-se nas partes superiores das estruturas, particularmente, onde praticamente não são estabelecidas frestas com acúmulo de eletrólito entre elas.

As regióes metálicas inferiores da $\mathrm{PMH}$ apresentam muito maior grau de degradação,

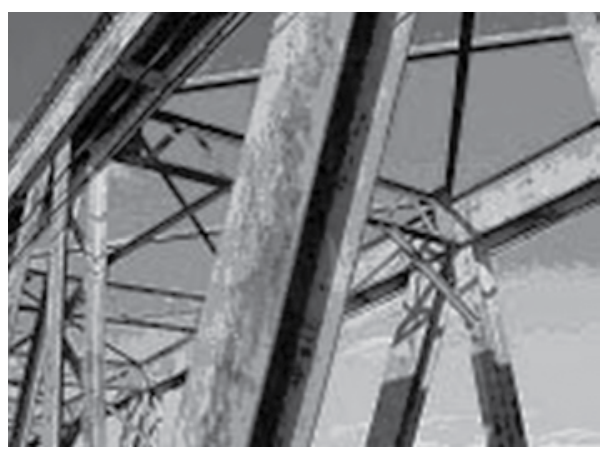

(a)

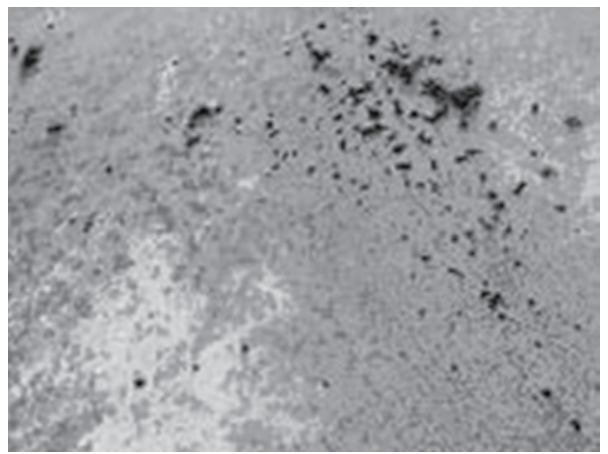

(b)

Figura 4. Corrosão generalizada nas estruturas metálicas da ponte - regiões superiores. 
particularmente em partes com frestas e acúmulo de substâncias que retêm eletrólitos. Destaca-se o efeito nocivo do contato metal/ madeira: a retenção de umidade intensifica $\circ$ ataque no material metálico, além de criar frestas. A Figura 5a-d apresenta este sistema de desenvolvimento de condições para o ataque do material e a Figura 6a,b mostra regiões onde ocorre acúmulo de eletrólito e são partes entre peças metálicas que propiciam o desenvolvimento de corrosão metálica.

A Figura 7a-d apresenta as regiões que estão sendo degradadas em função do acúmulo de eletrólito, onde os produtos de corrosão apresentam alta dissolução, ou seja, são facilmente destacados, possibilitando uma evolução contínua do processo corrosivo. Salienta-se, também, que nestes locais a estrutura se encontra sem qualquer tipo de proteção anticorrosiva, o que possibilita uma maior degradação do material. Notam-se regiões onde o sistema corrosivo (metal/meio) é gerado particularmente em junções e frestas.

A Figura 8a-d mostra alguns pontos críticos onde o fenômeno de corrosão tem sido desenvolvido em função de aspectos geométricos; nestes lugares são estabelecidas regiões de frestas. Este aspecto tem propiciado uma grande intensificação do fenômeno de corrosão no material metálico uma vez que são geradas pilhas de concentração e, também, acúmulo de eletrólitos.

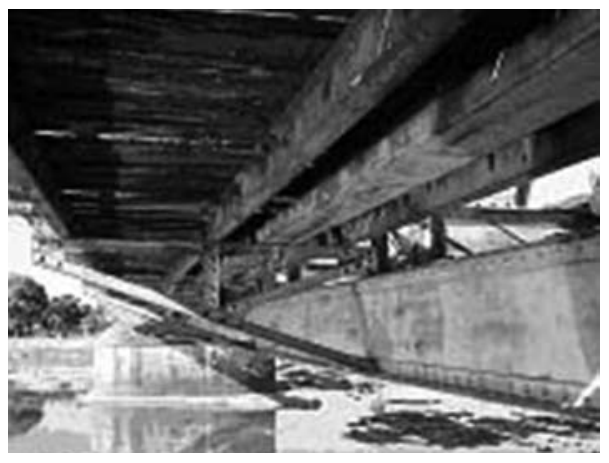

(a)

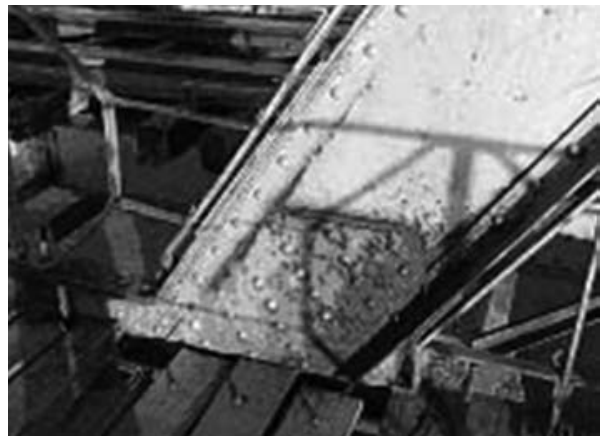

(b)

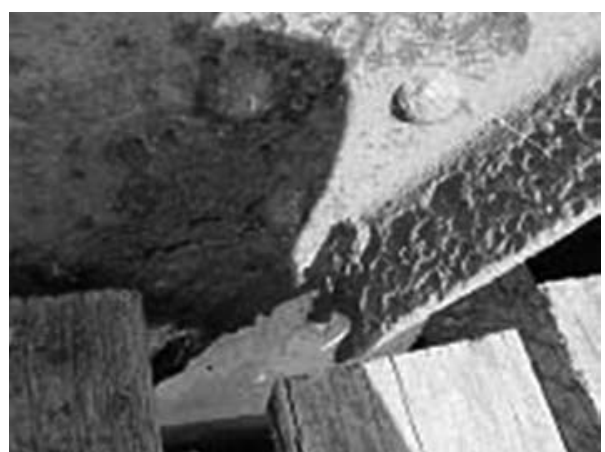

(c)

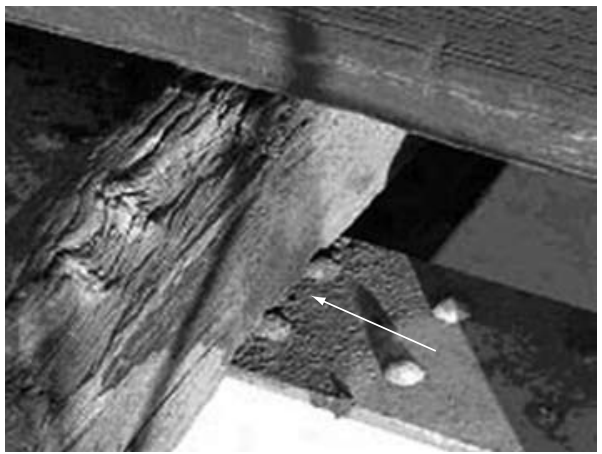

(d)

Figura 5. Sistema (metal/madeira) de desenvolvimento de condições ao ataque da ponte.

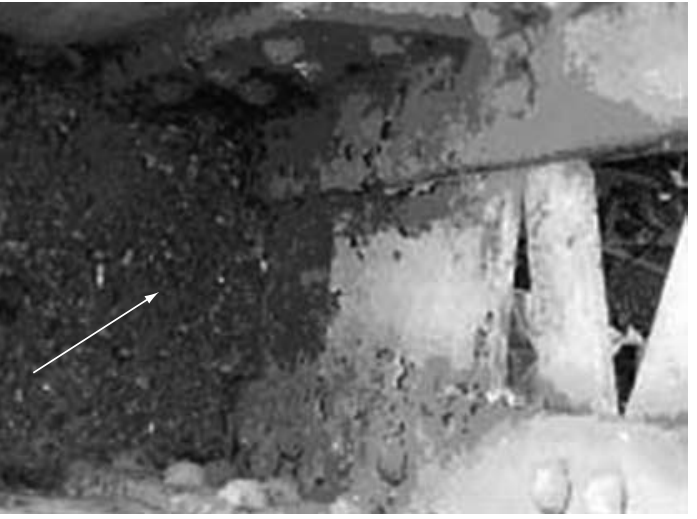

(a)

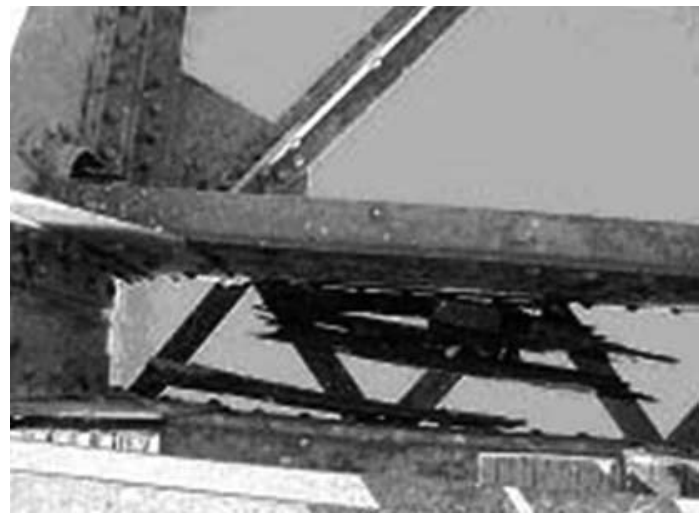

(b)

Figura 6. Lugares de retenção de materiais onde propicia o acúmulo de eletrólito e ataque do material. 


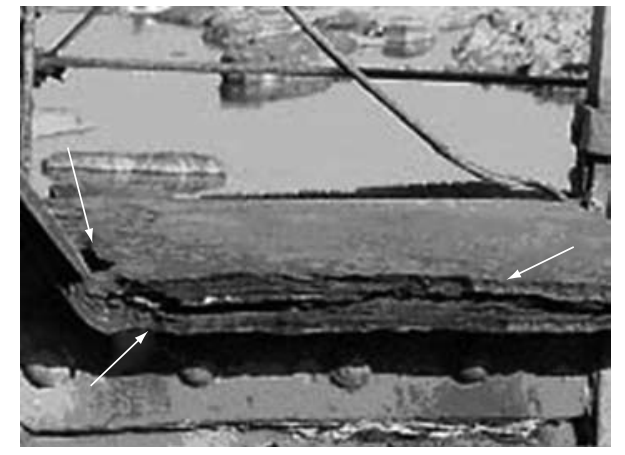

(a)

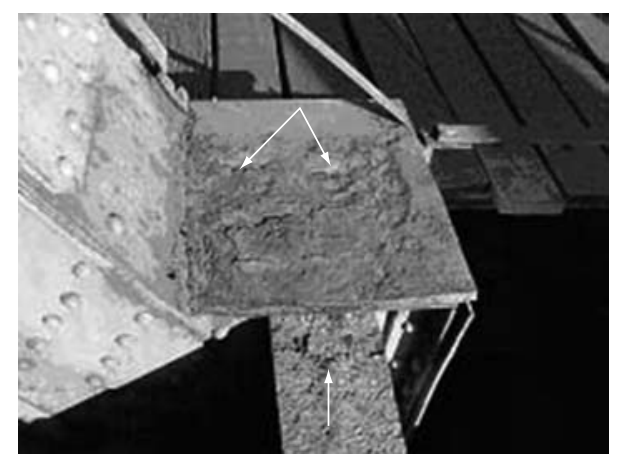

(b)

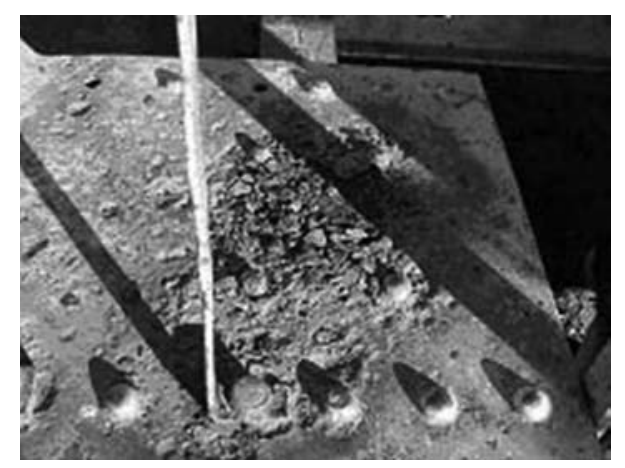

(c)

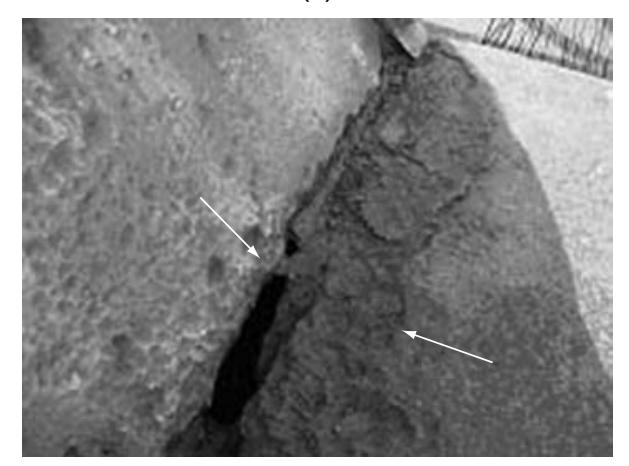

(c)

Figura 7. Ataque corrosivo em locais onde ocorre acúmulo de eletrólito.

É possível verificar, pela Figura 9a,b, que, em decorrência da evolução do fenômeno de corrosão em elementos estruturais da ponte, particularmente em regiões entre uniões onde geralmente são desenvolvidas frestas, o material sofreu intensa degradação,

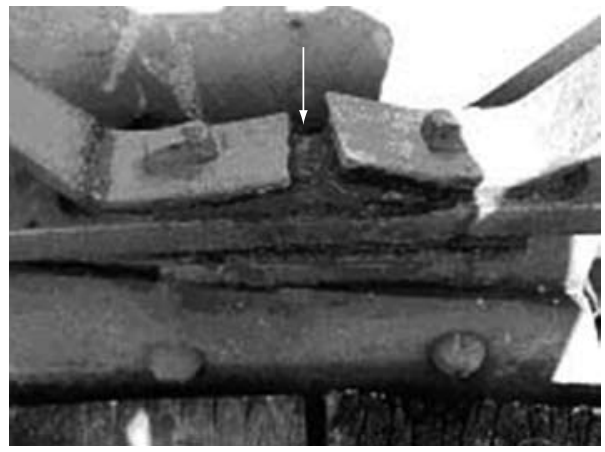

(a)

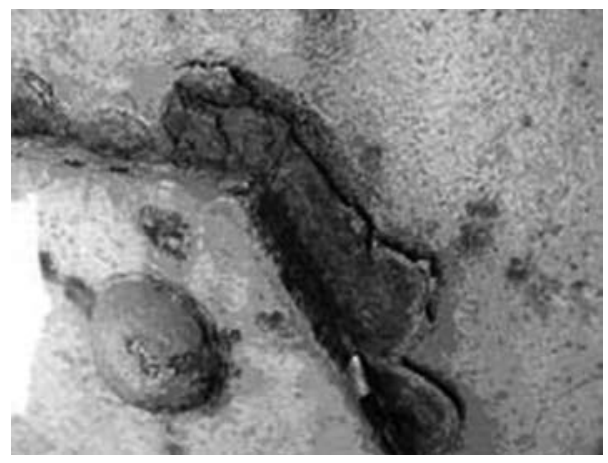

(b)

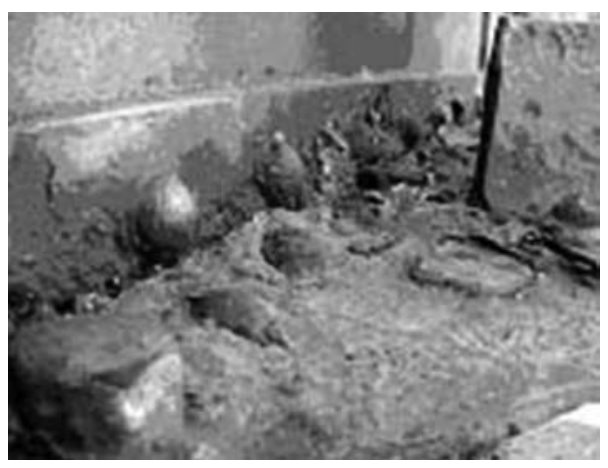

(c)

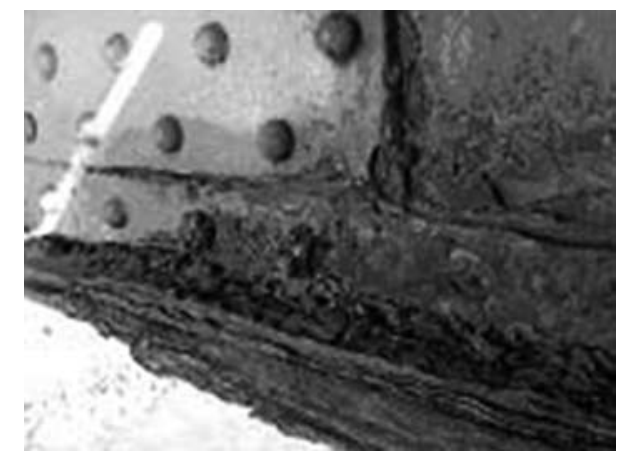

(c)

Figura 8. Desenvolvimento do fenômeno de corrosão em regiões de frestas.

chegando ao colapso. Notam-se que em algumas partes ocorreu separação, devido ao ataque corrosivo. Naturalmente, estes componentes deverão ser substituídos por elementos adequados para tal 


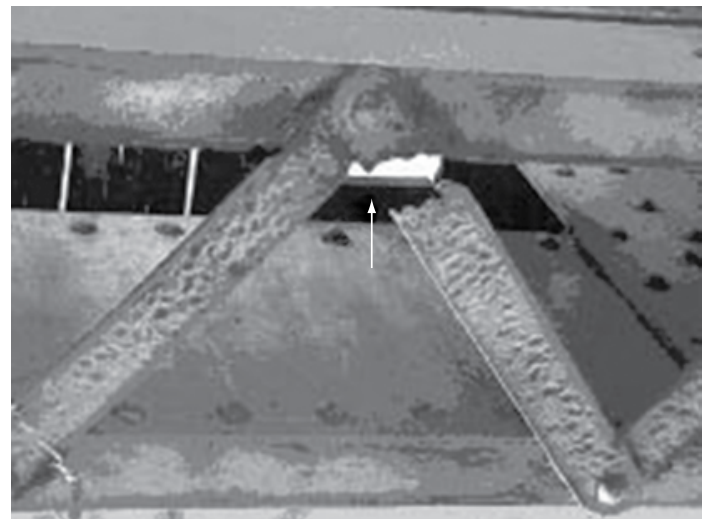

(a)

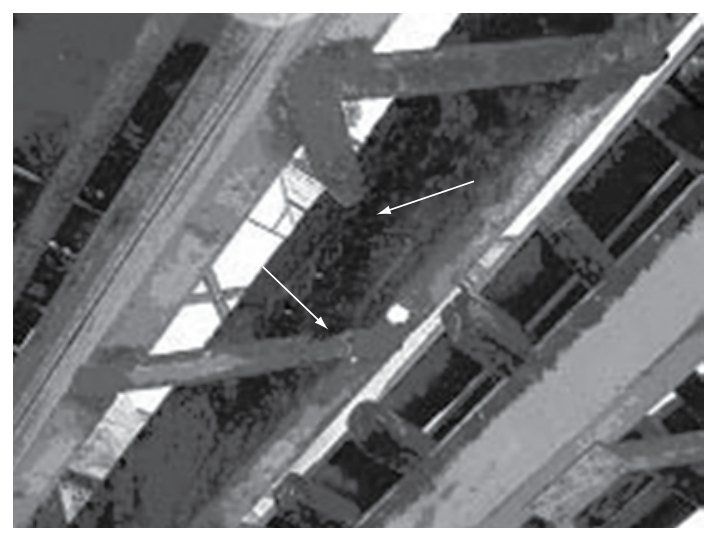

(b)

Figura 9. Efeito do ataque corrosivo em elementos de ligação da ponte; notase degradação total de alguns componentes.

finalidade. É importante salientar que o material metálico que irá compor a parte a ser substituida deverá apresentar características de resistência à corrosão semelhantes ao do material da ponte, no sentido de minimização do efeito do par galvânico que será estabelecido entre os elementos estruturais.

A Figura I 0 a,b mostra que o guarda-corpo da ponte também apresenta acentuado ataque corrosivo. A Figura 10a ilustra uma região onde, em função da geometria da estrutura, são criadas frestas que propiciam uma maior corrosão. A Figura $10 \mathrm{~b}$ mostra uma região onde a corrosão está ocorrendo acentuadamente no material, onde não há qualquer tipo de proteção anti-corrosiva.

Observou-se na ponte que existem regióes de destacamento da pintura, onde a corrosão da estrutura tem evoluído (Figura I I). Nota-se que em função da geometria da estrutura e do acúmulo de eletrólito tem-se uma intensificação do fenômeno de corrosão.

\section{CONCLUSÕES}

- Verificou-se que a Ponte Marechal Hermes encontra-se em elevado estado de degradação por corrosão, principalmente, em regiões onde ocorre acúmulo de eletrólito;

- Os locais com presença de frestas têm desenvolvido intenso ataque corrosivo. Nestas regiões desenvolvem-se

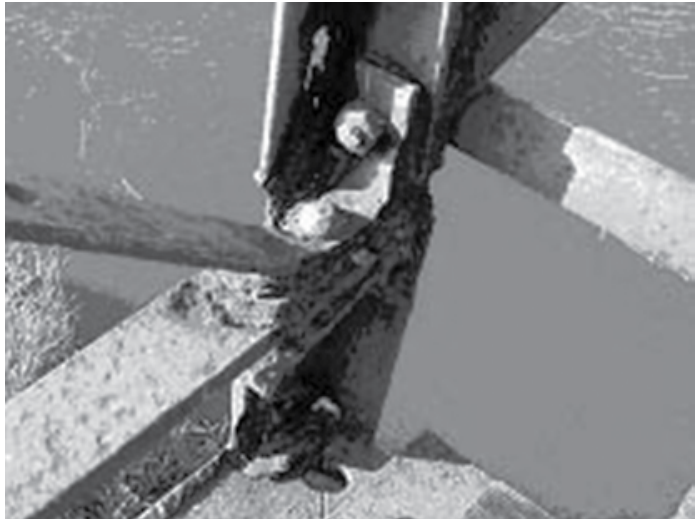

(a)

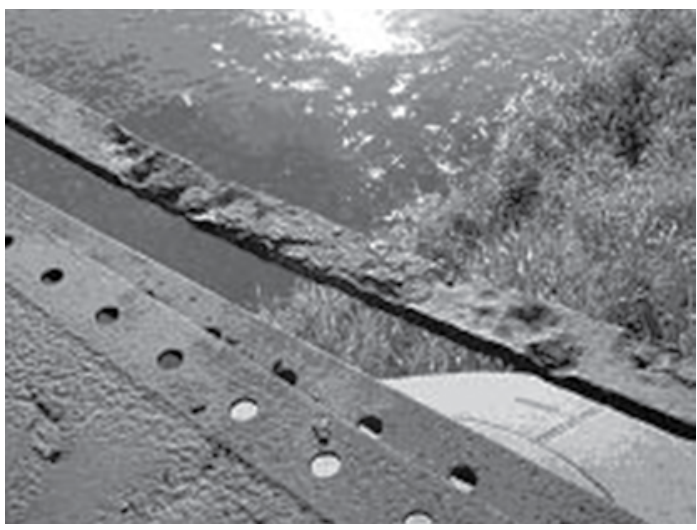

(b)

Figura 10. Corrosão metálica na região do guarda-corpo da Ponte Marechal Hermes.

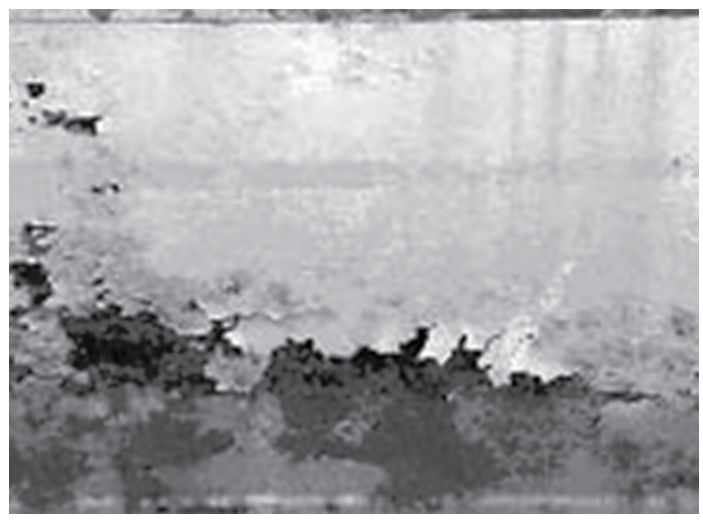

Figura II. Destacamento da pintura e ataque corrosivo no material da Ponte Marechal Hermes.

produtos de corrosão que atuam como concentradores de tensão provocando deformação e até ruptura de algumas peças que compõem os elementos estruturais; e

- Diante dos dados obtidos e da espontaneidade do fenômeno de corrosão é necessário que se faça manutenção periódica na Ponte Marechal Hermes. 


\section{REFERÊNCIAS}

I BATTISTA, R.C.; BARBOSA, F.S. Reabilitação de pontes metálicas ferroviárias por ação composta de lajes de concreto armado. In: JORNADAS SUDAMERICANAS DE INGENIERIA ESTRUCTURAL, 29., 2000, Punta del Leste. Porto Alegre: ASAEE, 2000. p. I-16.

2 BRINCK, F.M. Efeito da corrosão na integridade estrutural da ponte metálica Marechal Hermes. 2004. 177p. (Dissertação de Mestrado - Construções Metálicas) Ouro Preto: Departamento de Engenharia Civil da Universidade Federal de Ouro Preto, 2004.

3 CÂNDIDO, L.C. Patologias em estruturas metálicas,.Notas de aula do Ouro Preto: Departamento de Engenharia Metalúrgica e de Materiais da UFOP, 2002. (Notas de aula)

4 NEVES, F.A. Avaliação preliminar da ponte ferroviária metálica sobre o Rio São Francisco. Ouro Preto: Departamento de Engenharia Civil da Universidade Federal de Ouro Preto, 2001.

5 SARVESWARAN, V.; ROBERTS, M.B. Reliability analysis of deteriorating structures: the experience and needs of practicing engineers. Structural Safety, v. 21, p.358-372, 1998.

6 THIEL, M.E.; ZULFIGAR, K.; ENGELHARDT, M.D. Evaluation and reabilitation of historic metal truss bridges: survey of literature and current practices. Springfield: National Technical Information Service, 200I. (Technical report, FHWA/TX-0-I74I-I).

7 WOODWARD, R.J.; CULLINGTON, D.W.; DALY, A.F;; VASSIE, P.R.; HAARDT, P.; KASHNER, R.; ASTUDILLO, R.; VELANDO, C.; GODART, B.; CREMONA, C.; MAHUT, B.; RAHARINAIVO, A.; LAU; MARKEY, I.; BEVC, L.; PERUŠ, I. Deliverable DI4 final report. Berkshire: BRIME - Bridge Management in Europe, 200I. Disponível em: <http:// www.trl.co.uk/brime/d l4.pdf>. Acesso em: 20 fev 2008.

Recebido em: II/07/07

Aceito em: 19/02/08

Proveniente de: CONGRESSO ANUAL DA ABM, 6I., 2006, Rio de Janeiro, RJ. São Paulo: ABM, 2006. 